\title{
ALGORITMA ONE TIME PASSWORD PADA SISTEM INFORMASI PENERIMAAN SISWA BARU ONLINE SMP H.A. JOHANSYAH.A BANJARMASIN
}

\author{
Herry Adi Chandra ${ }^{1)}$, Yusup Indra Wijaya ${ }^{2)}$, Haldi Budiman ${ }^{3)}$ \\ ${ }^{1}$ Fakultas Teknologi Informasi Universitas Islam Kalimantan Muhammad Arsyad Al Banjari \\ Banjarmasin \\ email: herrysbc@gmail.com \\ ${ }^{2}$ Fakultas Teknologi Informasi Universitas Islam Kalimantan Muhammad Arsyad Al Banjari \\ Banjarmasin \\ email: yusupindra1313@gmail.com \\ ${ }^{3}$ Fakultas Teknologi Informasi Universitas Islam Kalimantan Muhammad Arsyad Al Banjari \\ Banjarmasin \\ email: haldibudiman01@gmail.com
}

\begin{abstract}
Abstrak
Untuk sebuah sekolah swasta yang selalu ramai saat masa pendaftaran siswa baru, SMP H.A. Johansyah.A Banjarmasin tentunya memerlukan sistem yang dapat memudahkan proses pendaftaran siswa baru karena data tersebut harus dilaporkan kepada kepala sekolah serta staff administrasi lainnya. Jika selama ini mereka hanya melakukannya dengan sistem pencatatan manual kemudian direkap dengan menggunakan microsoft excel hingga memerlukan waktu yang lebih lama ketika data dibutuhkan. Untuk mempermudah proses tersebut, kami merancang sebuah aplikasi pendaftaran siswa baru pada SMP H.A. Johansyah.A Banjarmasin berbasis web dengan menggunakan metode One Time Password untuk lebih meningkatkan keamanan serta sebagai validasi saat proses pendaftaran dilakukan secara online dan dengan adanya aplikasi ini diharapkan dapat memudahkan proses pendaftaran siswa baru nantinya.
\end{abstract}

Kata Kunci : Algoritma One Time Password, Sistem Informasi, Online

\section{PENDAhULUN}

\subsection{Latar Belakang}

Salah satu aktivitas akademik yang ada di sekolah pada umumnya setiap kali menjelang tahun ajaran baru tentunya adalah proses penerimaan siswa baru. siswa baru yang mendaftar di SMP H.A. Johansyah.A Banjarmasin sangatlah banyak serta mayoritas berasal dari luar kota. Kesulitan dalam hal peregistrasian tentu akan dialami oleh petugas penerimaan pendaftaran serta bagi siswa baru di sekolah tersebut. Untuk siswa baru yang berasal dari luar kota tentu harus datang ke sekolah tersebut untuk melakukan registrasi dan melakukan pembayaran uang pendaftaran.
Selama ini semua dicatat dengan cara manual. Tentu ini lebih memerlukan waktu yang lama, serta jarak tempuh yang lumayan jauh. Untuk memudahkan proses pendaftaran serta pembayaran administrasi maka diperlukan susatu sistem aplikasi penerimaan siswa baru untuk dibuat.

\subsection{Rumusan Masalah}

Berdasarkan latar belakang diatas, maka perlu suatu langkah untuk mempermudah kegiatan penerimaan siswa baru pada SMP H.A. Johansyah.A Banjarmasin tersebut .rumusan masalah yang akan diuraikan pada penelitian ini yaitu bagaimanakah aplikasi penerimaan siswa baru pada SMP H.A. Johansyah.A 
Banjarmasin ini dapat membantu setiap kegiatan penerimaan siswa baru dan administrasi pendaftaran pada sekolah tersebut dengan baik.

\subsection{Tujuan dan Target Luaran}

Tujuan dari penelitian ini adalah membuat suatu Perancangan Aplikasi Penerimaan Siswa Baru pada SMP H.A. Johansyah.A Banjarmasin adapun manfaat yang diharapkan yaitu : dengan dibuatnya aplikasi ini diharapkan dapat mempermudah proses pendaftaran siswa baru baik itu yang tinggal didalam kota maupun diluar kota, perekapan data siswa baru yang telah melakukan pendaftaran serta melakukan proses pembayaran administrasi sekolah.

Target luaran yang ingin dicapai oleh kami adalah Penelitian ini bisa masuk Prosiding Jurnal UNISKA .

\section{Definisi Kode One Time Password}

Menurut Irma, (2016) Kode OTP merupakan salah satu cara transaksi dalam dunia digital sekarang yang di fungsikan sebagai pin untuk keamanan. Biasanya Kode OTP (One time password - kunci digital sekali pakai ) atau pin tersebut di kirim ke nomor telepon atau di hubungi ke telepon kita langsung. Teknologi ini adalah penambahan security untuk mengatasi pencurian informasi.

Menurut Uung, (2016) Algoritma Time-Based One Time Password (TOTP) adalah salah satu algoritma yang memiliki kemampuan untuk menghasilkan password sekali pemakaian. Password yang dihasilkan oleh algoritma TOTP memiliki masa berlaku yang terbatas dan selalu berubah dalam periode tertentu. Cara kerja algortima TOTP yaitu menggabungkan antara secret key dengan current time kemudian dilakukan hashing menggunakan algoritma enkripsi SHA256. Algoritma TOTP merupakan implementasi dari Two Factor Authentication (2FA) yaitu menggabungkan dua metode otentikasi berbeda secara bersamaan. Otentikasi yang digabungkan adalah password statis sebagai akses login dan token device yang dibangun secara virtual sehingga dapat diaplikasikan pada smartphone Android. Pada penelitian ini 2FA diaplikasikan pada sistem internet banking di mana antara token virtual dan server dipasang algoritma TOTP untuk menghasilkan password sebagai otentikasi tambahan dalam proses transaksi finansial seperti pengiriman uang, pembayaran tagihan, dan pembayaran tiket. Sebelum transaksi diproses, server meminta user untuk memasukkan pssword OTP yang dihasilkan token virtual kemudian server melakukan validasi terhadap password OTP tersebut. Dari hasil pengujian yang dilakukan bahwa password OTP tidak muncul secara berulang dan secret key yang dihasilkan secara acak juga tidak muncul secara berulang tetapi mempunyai prosentasi kemiripan tertinggi sebesar $0,03 \%$.

\section{METODE PENELITIAN}

Metode penelitian dalam hal ini meliputi perancangan yang kemudian diwujudkan dengan menggunakan metode One Time Password.

Untuk analisa Kebutuhan Sistem Dalam Desain Aplikasi Penerimaan Siswa Baru pada SMP H.A. Johansyah.A Banjarmasin yang akan dibuat nanti diharapkan dapat menyelesaikan masalahmasalah yang dihadapi. Dengan demikian akan membuat beberapa menu guna mempermudah dalam sistem kerja dan agar dapat melangsungkan pengetesan secara baik, serta kebutuhan yang sesuai dengan keinginan.

Menu yang ada di aplikasi diantaranya adalah :

- $\quad$ Menu Log In Admin.

- $\quad$ Menu Input Data Siswa Baru.

- Dan lain lain yang disesuai kan

dengan kebutuhan Sekolah nantinya

\section{Teknik Pengumpulan Data dan Peralatan}

Teknik untuk memperoleh data dengan melakukan: 
1. Observasi langsung dengan mengambil data sekolah.

2. Peta Administrasi kota Banjaramasin

3. Studi Literatur

Adapun beberapa hardware dan software yang digunakan adalah

1. Perangkat Keras (hardware)

a) Laptop Toshiba 16 Inc

b) Printer untuk mencetak laporan

2. Perangkat Lunak (software)
a) Microsoft Office 2016
b) Sublime Text 3
c) CodeIgniter

\section{HASIL DAN PEMBAHASAN}

\section{Tahapan Pembuatan}
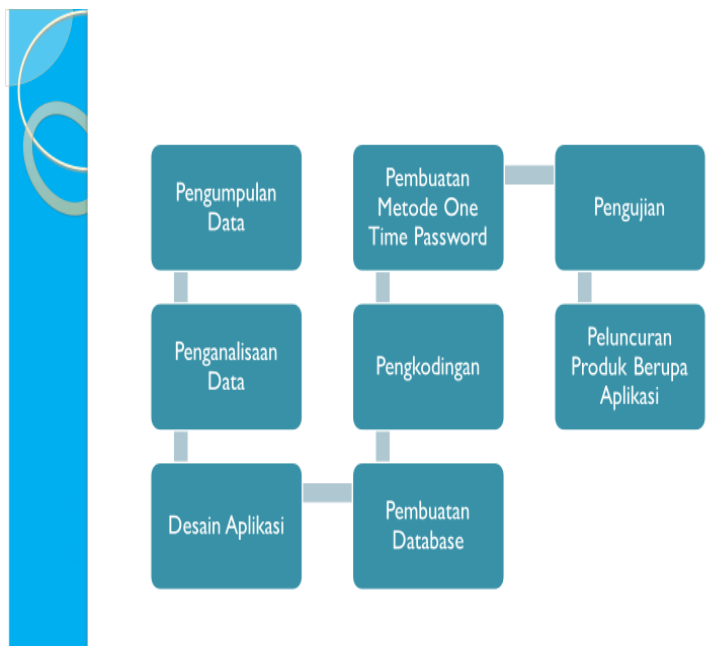

\section{Perancangan Desain Sistem}

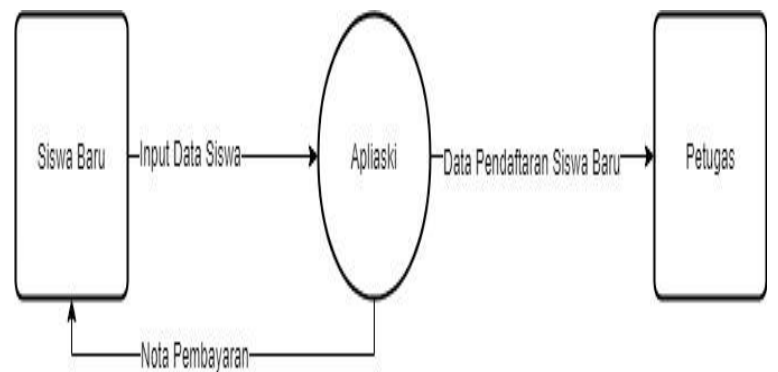

Diagram Flow Diagram (diagram konteks kebutuhan sistem)

\section{Perancangan Flowchart}

Flowchart merupakan suatu diagram yang menggambarkan alur kerja suatu sistem. Berikut flowmap yang dibuat untuk mendukung aplikasi ini.

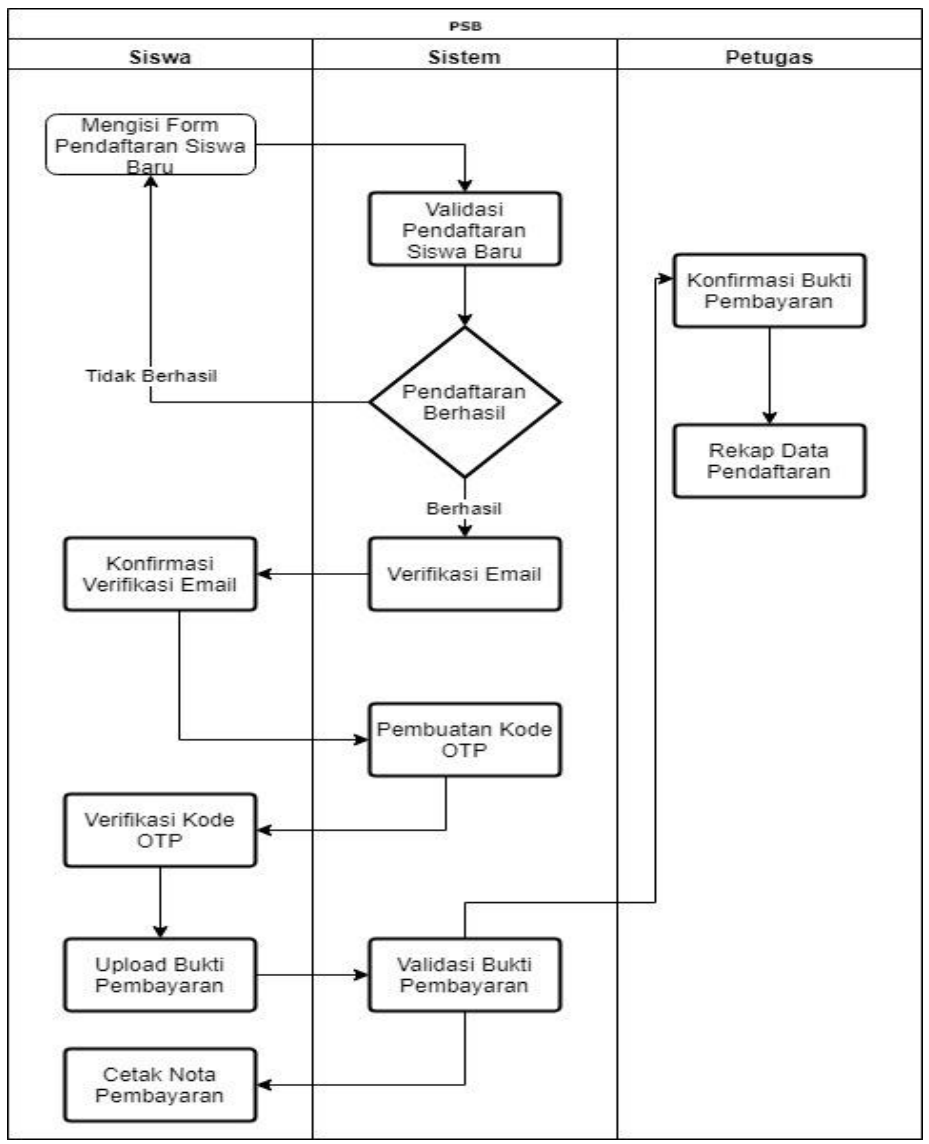

Flowmap Sistem Aplikasi Penerimaan Siswa Baru

\section{Tampilan Menu Utama}

\section{(3) SMPH.J.JHANSYAH.A}




\section{Tampilan Login Admin}

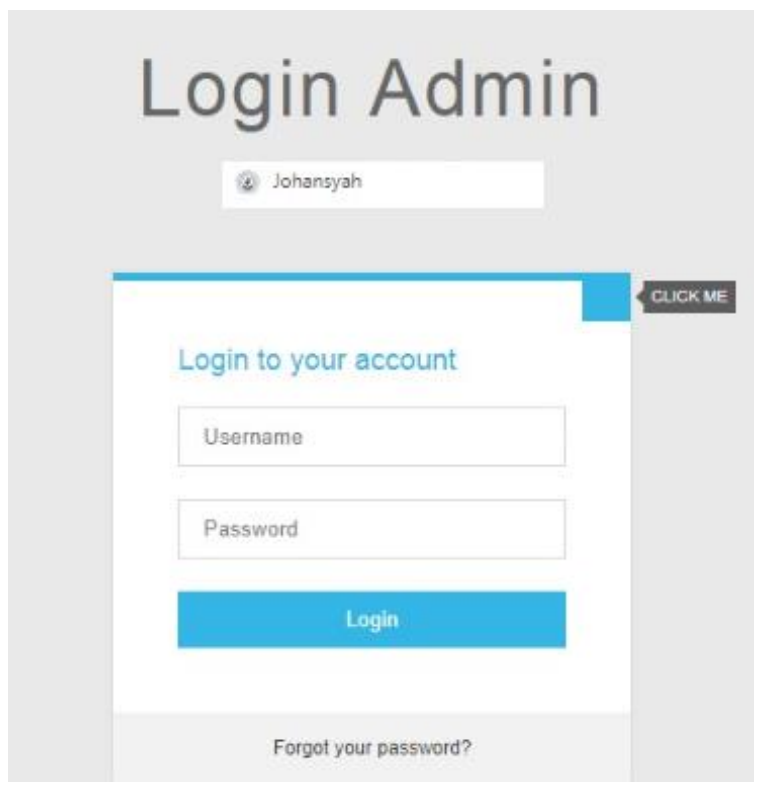

Tampilan Menu Home Admin
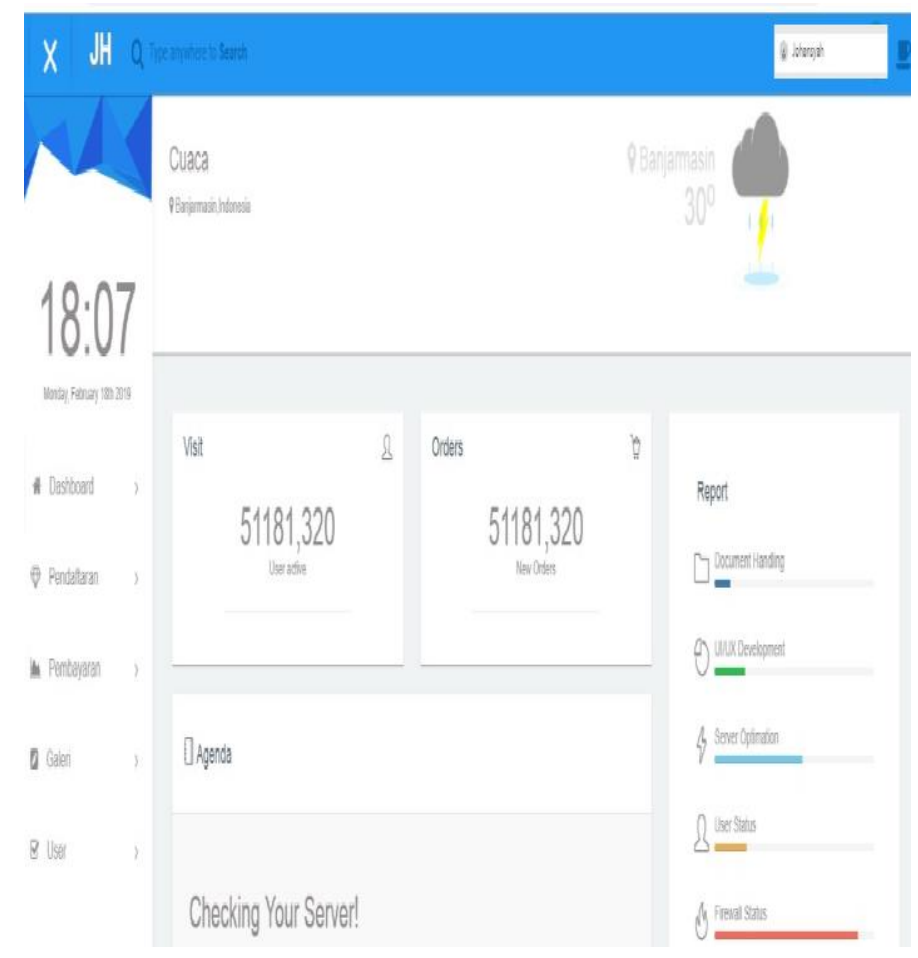

\section{KESIMPULAN}

Dengan Adanya Sistem Informasi Penerimaan Siswa Baru Online Berbasis One Time Password ini diharapkan dapat mempermudah para calon siswa baru untuk melakukan pendaftaran secara online dan juga sebagai media promosi untuk sekolah agar dapat meningkatkan jumlah siswa, serta kualitas dan kuantitas para calon siswa baru.

\section{REFERENSI}

[1]. Mohsen Gerami, S. G. (2016). One Time Password via SMS. Bulletin de la Societe Royale des Science de Liege, 106-113.

[2]. Nugroho, I. (2011). Sistem Informasi Penerimaan Siswa Baru Berbasis 
Web dengan PHP dan MYSQL. SKRIPSI, 1-260.

[3]. Pribadi, J. A. (2015). Sistem Informasi Pendaftaran Siswa Baru Berbasis Web (Studi Kasus : SMAN 1 PACITAN). Jurnal Referensi, 1-14.

[4]. Regi Witanto, H. H. (2016). Perancangan Sistem Informasi Penerimaan Siswa Baru Berbasis Web. Jurnal Infotronik, 54-63.

[5]. Santoso. (2014). Sistem Informasi Pendaftaran Siswa Baru Pada SMK Diponegoro Tulakan. Speed Journal, 42-48.

[6]. Seok Hee Jeon, S. K. (2016). Optical One-time Password Authentication Using Digital Holography. Journal of the Optical Society of Korea, 722-732.

[7]. Shally, G. S. (2014). A Review Of One Time Password Mobile Verification. International Journal of Computer Science Engineering, 113-117.

[8]. Uung Ungkawa, I. A. (2016). Implementasi Algoritma TimeBased One Time Password Dalam Otentikasi Token Internet Bangking. Itenas Library, 1-10.

[9]. Yun Huang, Z. H. (2013). A new One-time Password Method. International Conference on Electronic Engineering and Computer Science, 32-37.

[10]. Yusuf Abdullahi, M. B. (2017). Responsive Time Improvment on
One Time Password(OTP) Technique to Prevent Replay Attack in a Radius Environment British Journal of Applied Science \& Technology, 1-37. 